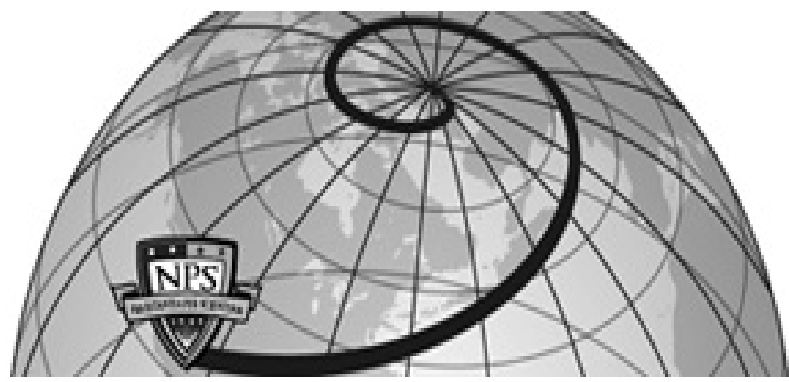

Calhoun: The NPS Institutional Archive DSpace Repository

\title{
Workplace Drug Prevention Programs: Does Zero Tolerance Work?
}

Mehay, Stephen; Webb, Natalie J.

Monterey, California: Naval Postgraduate School.

https://hdl.handle.net/10945/32545

This publication is a work of the U.S. Government as defined in Title 17, United States Code, Section 101. Copyright protection is not available for this work in the United States.

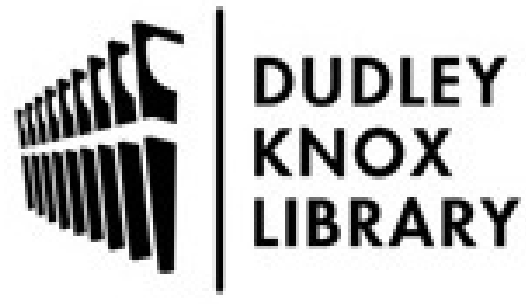

http://www.nps.edu/library
Calhoun is the Naval Postgraduate School's public access digital repository for research materials and institutional publications created by the NPS community. Calhoun is named for Professor of Mathematics Guy K. Calhoun, NPS's first appointed -- and published -- scholarly author.

Dudley Knox Library / Naval Postgraduate School 411 Dyer Road / 1 University Circle Monterey, California USA 93943 


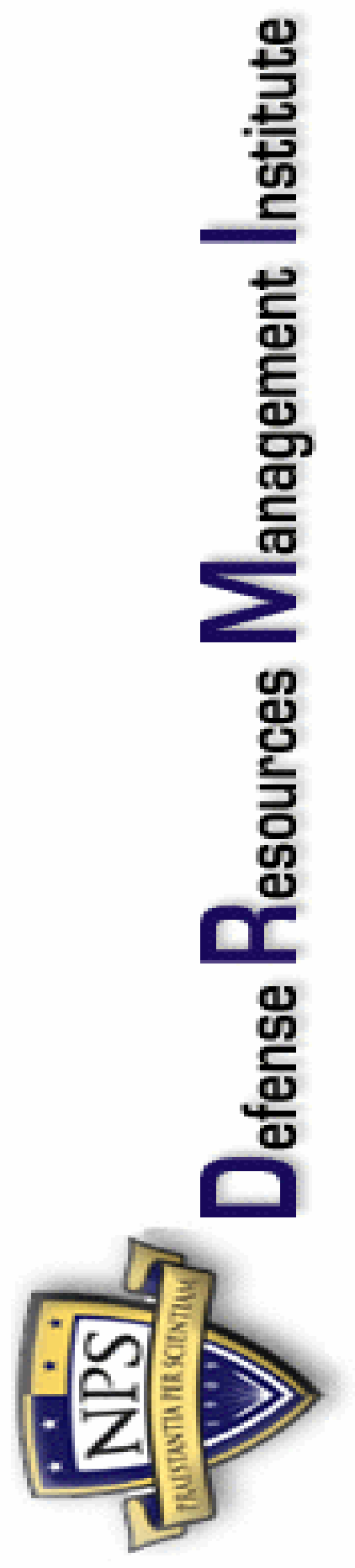

\title{
WORKING PAPER SERIES
}

\author{
$2005 / 10$
}

\section{Workplace Drug Prevention Programs: Does Zero Tolerance Work?}

\author{
Stephen Mehay and Natalie J. Webb
}

\begin{abstract}
Current drug policy in the U.S. military mandates frequent random drug testing of service members and dismissal of those who test positive for illegal drugs. This paper analyzes the economic costs and benefits of this zero tolerance policy as applied in the U.S. Navy. Program effects consist of the actual number of detected users and the predicted number of deterred potential users. Productivity losses imposed by drug users are based on reported annual workdays lost due to drug use in the Navy. The productivity losses avoided by deterring and detecting users constitute program benefits. Program costs include the cost of replacing service members who are dismissed under the zero tolerance policy. Net benefits are sensitive to three key parameters -- the deterrence effect, replacement cost, and productivity losses due to drug use. The results show that net benefits are negative for most plausible values of the key parameters.
\end{abstract}

Defense Resources Management Institute
School of International Graduate Studies
Naval Postgraduate School
Building 234
699 Dyer Road
Monterey, CA 93943-5138
831-656-2306
www.nps.navy.mil/drmi

The views herein expressed reflect the views of the author and are not the policy of DRMI, the Naval Postgraduate School, or the U.S. Government. 


\section{Defense Resources Management Institute Naval Postgraduate School}

The Defense Resources Management Institute (DRMI) is an educational institution sponsored and supervised by the Secretary of Defense and located at the Naval Postgraduate School in Monterey, California. Since 1965 the Institute has conducted professional education programs in analytical decision making and resources management for military officers of all services and for senior civilian officials of the United States and 149 other countries.

The mission of the Defense Resources Management Institute is to educate civilian and military government officials in the principles and concepts of defense resources management.

The unique course offerings create an interdisciplinary, interactive learning environment that facilitates the exchange of ideas among U.S. and international participants in Monterey, California, and locations worldwide. These programs are presented on a regularly scheduled basis at DRMI in Monterey and by specific arrangement at other locations in the United States and in other countries.

The success of DRMI reflects the breadth and depth of the in-house technical expertise that DRMI can draw upon. The DRMI Faculty, a community of scholars and practitioners, are experts in defense resources management and has published in major academic and technical journals. The faculty has extensive experience in providing technical assistance and educational programs worldwide over the past 40 years. Our educational strategy is one of collaboration, tailored to the specific environment of the participant.

The Defense Resources Management Institute specializes in four broad educational areas:

- Economic analysis of the public sector

- Operations research of public sector decision problems

- Public budgeting and fiscal management

- Defense organizations and management methods

For more information about our educational and technical assistance activities, please visit our website at http://www.nps.navy.mil/drmi or email us at drmiadmin@nps.edu. 


\title{
Workplace Drug Prevention Programs: Does Zero Tolerance Work?
}

\author{
RUNNING HEAD: Workplace Drug Prevention Programs: \\ Does Zero Tolerance Work?
}

\begin{abstract}
:
Current drug policy in the U.S. military mandates frequent random drug testing of service members and dismissal of those who test positive for illegal drugs. This paper analyzes the economic costs and benefits of this zero tolerance policy as applied in the U.S. Navy. Program effects consist of the actual number of detected users and the predicted number of deterred potential users. Productivity losses imposed by drug users are based on reported annual workdays lost due to drug use in the Navy. The productivity losses avoided by deterring and detecting users constitute program benefits. Program costs include the cost of replacing service members who are dismissed under the zero tolerance policy. Net benefits are sensitive to three key parameters -- the deterrence effect, replacement cost, and productivity losses due to drug use. The results show that net benefits are negative for most plausible values of the key parameters.
\end{abstract}

August 23, 2005

Stephen Mehay

School of Business and Public Policy

Naval Postgraduate School

555 Dyer Road

Monterey, CA 93943

831.656.2643

e-mail: smehay@nps.navy.mil
Natalie J. Webb

Defense Resources Management Institute Naval Postgraduate School 699 Dyer Road Monterey, CA 93943

831-656-2013

e-mail: njwebb@nps.navy.mil 


\section{Workplace Drug Prevention Programs: Does Zero Tolerance Work? I. INTRODUCTION}

The number of firms and government agencies in the U.S. adopting programs to combat substance abuse in the workplace has increased steadily over time. The percentage of medium- to large-sized U.S. firms using some form of drug testing nearly doubled in the 1990's following passage of the Drug Free Workplace Act of 1988, which requires companies with federal contracts to make appropriate efforts to maintain a drugfree workplace (Hartwell et al. 1996). ${ }^{1}$ The types of testing programs vary considerably: some organizations require tests of job applicants, others impose 'probable cause' tests, and still others, especially those in the utility and transportation sectors, require periodic or random testing of all employees. ${ }^{2}$ A small number of employers, most notably the military, have implemented a zero tolerance policy that combines aggressive drug testing with dismissal or prosecution of drug-positive workers. Despite the widespread use of drug testing and other workplace interventions, and the legal controversies surrounding them (Lieberwitz, 1994), there is scant research on the effects of these programs or their efficiency.

This paper explores the economic costs and benefits of a particularly aggressive workplace drug prevention program that has existed in the U.S. military since 1981 (Bray et al. 1992). The military mandates regular random drug testing of current service members and imposes severe penalties on those who test positive for drugs. Penalties range from dismissal, which may bar the individual from future government employment and from collecting veterans' benefits, to court martial, which carries jail time or fines. Despite the popularity of the zero tolerance concept, the welfare gains or losses of such 
programs have not been evaluated in the literature. The military's drug policies offer a unique natural experiment for studying a zero tolerance policy.

The goal of a punitive policy such as zero tolerance is to increase the probability of detection of current drug users and to impose sanctions to deter potential drug users. Economic benefits of the program depend on the size of the deterrence and detection effects. To assess the size of the deterrence effect empirically we estimate annual differences in illicit drug use between military and civilian workers based on data from the National Household Survey of Drug Abuse (NHSDA) and the U.S. Defense Department's Worldwide Health Survey. To assess the detection effect we obtain data on the actual number of users detected in the Navy for a given year. We use estimates of work time lost due to drug use to monetize the benefits associated with deterrence and detection. Because of the assumptions necessary to calculate program benefits and costs, we conduct a sensitivity analysis of the robustness of annual net benefit estimates. Although the analysis relies on data from the Navy's program, the results should be representative of effects across the military.

This paper is structured in the following way. Section II describes the statistical methodology for estimating the deterrence effect while Section III monetizes the benefits of detecting and deterring drug users. Section IV describes the costs of the zero tolerance policy and Section $\mathrm{V}$ analyzes the sensitivity of annual costs and benefits to alternate assumptions. Section VI concludes that, for plausible values of the key parameters, annual net benefits of the zero tolerance/testing policy are negative. 


\section{ESTIMATES OF THE DETERRENCE EFFECT}

Illicit drug use among active duty personnel dropped steadily following implementation of the military's strict intervention program in 1981. Military drug prevalence rates fell from 27.6 percent in 1980 just prior to introduction of the drug program, to 8.9 percent in 1985 shortly after implementation, to 3.4 percent in 1992 (Bray and Marsden, 1995). Although the reduction in drug use in the armed forces appears to have been associated with the drug program, data from the NHSDA show that civilian prevalence rates also declined during this period. Hence, it is not known what portion of the drop in military drug use is due to the program and what portion is explained by reductions in drug consumption among the general civilian youth population.

Goldberg et al. (2003) is one of the few prior studies to statistically assess the deterrence effect of a drug testing program. The authors compare self-reported pre- and post-treatment drug use rates of student athletes in two Oregon high schools, one that tested athletes and one that did not. Comparing the pre- and post-test differences in drug use in the tested and non-tested groups, the authors find a significant deterrence effect of 15 percentage points. Note that the high school drug program differs sharply from the military program in that the penalties are far less severe - drug-positive athletes are referred to their parents and allowed to remain on their high school athletic teams.

Estimates of the deterrence effect in this paper are based on the difference in drug use between the military and civilian sectors. To analyze drug use in the civilian population we use data from the NHSDA. In addition to collecting socioeconomic and demographic information, the NHSDA asks a series of questions pertaining to lifetime, 
past-year, and past-month non-medical use of 11 or more illicit substances including marijuana, cocaine, crack, inhalants, hallucinogens, PCP, heroin, stimulants, sedatives, tranquilizers, and analgesics (SAMHSA, 1996).

Drug prevalence rates among active duty military personnel are derived from the Defense Department Worldwide Health Survey (DHS). Questions that pertain to illicit drug use in the DHS are structured the same as those in the NHSDA (Bray et al., 1992). In addition, a number of standard demographic measures are available in both surveys. A binary indicator of each respondent's drug participation is based on positive responses to questions on the non-medical use of one or more of 11 illegal substances in the past 12 months.

One method of analyzing the impact of the policy change on drug use is the difference-in-difference framework. This approach involves comparing the change in behavior in the military sector, where the zero tolerance 'treatment' was implemented, with the change in behavior in the civilian sector, where drug testing is less extensive or absent and where zero tolerance policies are rare. The greater certainty and severity of punishment in the military should increase the cost of using drugs to service members and reduce drug prevalence rates in the military relative to the civilian workforce. ${ }^{3}$

Difference-in-differences estimates are obtained by merging data from the NHSDA and DHS surveys and analyzing military-civilian drug use differences in preand post-program years. We estimate pre-program military-civilian differences using merged data from the 1980 DHS and the 1979 NHSDA surveys. For the pre-program period we were forced to merge two different years as the DHS and NHSDA surveys were not fielded in the same years. We chose 1979/1980 because these years 
immediately preceded the introduction of the military's program and also because they represent years in which the national trend in drug use remained unchanged. ${ }^{4}$ We chose 1995 for the post-program year in part because military drug policies underwent significant revisions during the 1980's and early 1990's, both within the individual services and across the Department of Defense (DOD). ${ }^{5}$ The choice of 1995 data allows time for drug policies to become standardized among and within the military branches and thus for a more reliable evaluation of the policy's long-run impact on drug behavior.

The NHSDA samples were restricted to 17 - to 49-year olds males to align the age and gender distribution of the civilian and military samples. Since military drug test results indicate that 99 percent of drug usage occurs among enlisted personnel, the DHS samples include only enlisted personnel. Finally, since most enlisted personnel work in blue-collar occupations, the NHSDA comparison group includes only in blue-collar workers.

Table 1 presents the means of the variables in the data set divided into the military and civilian sectors, before and after the policy change. As the first two rows show, the policy change was associated with a significant decrease in military drug use. Although drug use also declined in the civilian sector, it fell much faster in the military: past month use fell by $90 \%$ in the military but by only $60 \%$ in the civilian sector; similarly, past-year use fell by $84 \%$ in the military but by only $54 \%$ in the civilian sector.

Difference-in-difference estimates are derived from a linear probability model of the following form:

$$
\text { DRUG }_{i}=\beta_{0}+\beta_{1} \text { MIL }+\beta_{2} \text { YEAR95 }+\beta_{3} \text { MIL x YEAR95 }+\beta_{4} X_{i}+e_{i}
$$


where DRUG $_{\mathrm{i}}$ is a dummy for drug use by person i, MIL is an indicator for a military service member, YEAR95 is an indicator of whether the year is after the policy change, and $\mathrm{X}_{\mathrm{i}}$ is a set of covariates for person $\mathrm{i}$ (age, marital status, education, gender, race/ethnicity). In this framework, the coefficient of $\beta_{3}$ measures the effect of being in the military, relative to being in the civilian sector, after the zero tolerance policy, relative to before. That is, the coefficient of the military-year interaction measures the change in drug behavior of personnel who work under a zero tolerance policy versus the change for civilians who are not subject to equally punitive policies. The results are presented in Table 2.

The results for the control variables in Table 2 have the expected effects and indicate that Hispanics, married persons, and members of the 'other' race/ethnic group are less likely to use drugs. The age and education dummies (not shown) also have the expected pattern with older and more educated persons less likely to use drugs. The coefficient of the interaction term indicates a program effect of 9.82 percentage points. As a reference point, the Goldberg et al. (2003) study of student athletes estimated a deterrence effect of 15 percentage points.

The data used here are based on self-reported surveys, which are known to understate actual drug use (Bray et al. 1992; Harrison and Hughes, 1997). However, the issue here is the relative underreporting in the NHSDA and DHS surveys. The main difference between them is that military personnel are responding to a workplace survey. Cook, Bernstein, and Andrews (1997) claim that underreporting on workplace drug surveys can be particularly high. The authors compare the results of self-reports and urinalysis tests of employees at a single manufacturing plant. Their data show that while 
self-reported illicit drug use rates are $9.4 \%$, rates based on urinalysis tests are only $7.8 \%$ suggesting that overreporting, not underreporting, is the problem. However, the authors compute what they consider the 'true' prevalence rate by adding all self-reported users to those who tested positive on the urinalysis but who failed to self-report usage. This yields a 'true' drug use rate of $14.2 \%$, leading them to conclude that underreporting in workplace settings is about $50 \%$.

This conclusion, however, is marred by some inconsistencies in their method. For users who tested positive but who did not self-report, they accept the results of the urinalysis; on the other hand, for those who tested negative on the urinalysis, they accept the individual's self-report in lieu of the urinalysis result. Second, the authors compare individuals tested via urinalysis with those tested via hair analysis, which are not comparable testing methods. When these inconsistencies are eliminated, the true prevalence rate in their data is $11.3 \%$, suggesting underreporting of about $20 \%$.

Because the authors examine various interview techniques to obtain the selfreported rates, and two types of laboratory tests, it is difficult to accept their conclusion that the true rate is $14.2 \%$ (compared to the self-reported rate of 9.4\%). Moreover, the underreporting they observe is likely to exist in both the DHS and the NHSDA and, therefore, their evidence cannot be considered conclusive on the relative measurement error in the two surveys. Harrison (1997, p. 30) surveys validation studies and concludes that "at this point, it is not possible to judge how validly individuals report their drug use in surveys.” Despite the lack of evidence on underreporting in the two drug surveys, to allow for the possibility of differences in self-reporting in the DHS, we estimate the deterrence effects with and without an adjustment for underreporting. We account for 
underreporting by reducing the difference-in-difference program effect by $20 \%$, the lower figure from the Cook, Bernstein, and Andrews (1997) study, which yields an adjusted deterrence effect of 7.88 points. This adjustment creates a lower-bound estimate of the deterrence effect.

The approach above uses the entire civilian workforce as the comparison group. One problem with this approach is that some civilian NHSDA respondents work in industries that routinely apply drug testing. Unfortunately, we have little specific information on the type or extent of drug testing policies by broad industry category. It is known, however, that drug testing is more widespread in the transportation industry therefore we experimented by omitting respondents in the transportation industry from the civilian sample. This alteration had very little effect on the basic difference-indifference estimates. ${ }^{6}$

\section{BENEFITS OF ZERO TOLERANCE}

The benefits of a workplace drug prevention program hinge on the gain in worker productivity when the program successfully reduces drug abuse. Monetizing benefits first requires estimates of worker productivity losses due to drug use. Prior studies that have analyzed productivity differences between drug-using and drug-free employees have produced conflicting results. Some studies have discovered a link between drug use

and degraded performance, which has been attributed to greater absenteeism, reduced job performance, higher accident and injury rates, greater use of medical benefits, and lower job retention (Zwerling, et al., 1992; Martin, et al., 1994). However, the methodologies 
and conclusions of many of these studies have been challenged (Horgan, 1990), and the National Academy of Sciences could find no clear evidence that drug use reduces safety or other job performance indicators (Normand, 1994, p. 107).

To estimate productivity losses in the military associated with drug consumption we assess the responses to questions in the DHS on the negative job consequences of drug or alcohol use. ${ }^{7}$ An index of work days lost due to drug use was constructed based on five questions in the DHS. The questions record the number of times the respondent was late to work, left work early, was hurt in an accident, was absent from work, or performed below normal due to drug use. Each response was weighted by the number of days, or portion of a day, assumed to be lost for each reported incident and summed to create the annual number of days lost per drug-using worker. ${ }^{8}$ For the sample, the average number of days lost annually due to drug use was 9.15 (or 3.7\% of annual work days) per drug-using worker. ${ }^{9}$

Because of considerable evidence in the literature of comorbidity between drugs and alcohol (Martin et al. 1994) the measure of days lost due solely to drug use may understate the true amount of lost output. To allow for comorbidity we create a second estimate of output loss by adding work days lost due to alcohol use to the previous index (using the same weighting scheme). The average combined number of days lost due to both alcohol and drugs per drug-using worker was 23.12 (or 9.2\% of annual work days). ${ }^{10}$ These two 'productivity degradation' factors $-3.7 \%$ and $9.2 \%$-- establish the range used below to perform partial sensitivity analyses of the impact of productivity losses on net benefits. 
A range of degradation estimates is needed due to the inherent uncertainty of the true performance loss in the military. As pointed out above, numerous studies have found no evidence of damages due to workplace drug use in civilian firms. On the other hand, the Navy is not comparable to private firms. One difference is that safety is an important issue in the daily operation of ships, aircraft, and submarines and the associated weapons and nuclear power systems. Military personnel also handle classified material. Furthermore, due to the importance of team production in the military, absenteeism and degraded performance will affect overall unit performance and readiness. These full effects are difficult to evaluate but are assumed to be bracketed by the range of losses established by the two productivity degradation indexes.

\section{A. Monetary Benefits of Detecting Drug Users.}

To derive indicators of the costs avoided by deterring and detecting drug users, we first estimate average earnings per enlisted person. Information on the 5,416 Navy enlisted personnel detected and dismissed due to non-medical drug use in 1999 was obtained from the Defense Manpower Data Center (DMDC). We assume that detected personnel represent a sample of the target population of the military's drug policy, which allows us to use the grade distribution of detected service members to calculate weighted average annual earnings for all enlisted personnel. The earnings measure includes base pay, and allowances for housing and subsistence. Weighted average annual earnings in 1999 were $\$ 22,745$. Multiplying the productivity degradation factors by average annual earnings yields the per person losses from drug use (and the costs avoided from successful prevention). Annual per person output losses are valued at $\$ 841$ for the lower bound degradation factor and \$2,092 for the upper bound. ${ }^{11}$ 
In 1999 there were 314,272 Navy enlisted personnel, of whom 5,416 (1.7\%) were detected and terminated for failing the urinalysis test. This number represents gross detections, but we must use net detections by adjusting for the number of replacements who themselves will be drug users. We assume that the prevalence rate among new recruits is four percent, about one point lower than the overall Navy prevalence rate of five percent. This yields 5,199 net detected members. Annual benefits to the Navy of detecting and terminating 5,199 drug users in 1999 range from \$4.37 million under the low degradation factor to $\$ 10.87$ million under the high degradation factor.

\section{B. Monetary Benefits of Deterring Potential Drug Users.} Since 5\% of Navy personnel used drugs in 1995, the estimated deterrence effect of 9.82 points implies that the prevalence rate would have been 14.86 percentage points in the absence of the program, and that 30,987 potential users were deterred annually. The product of the number of deterred personnel and the costs avoided per person yields annual deterrence benefits of \$26.07 million and \$64.84 million for the low and high degradation factors, respectively. Panel A of Table 3 summarizes gross benefits to the Navy, which range from \$25.21 million under the low degradation/low deterrence combination (column 4), to \$75.71 million under the high deterrence/high degradation combination (col. 2). It is noteworthy that the benefits associated with deterrence far outweigh the benefits generated by detecting current users. ${ }^{12}$

\section{THE COST OF DRUG TESTING AND ZERO TOLERANCE}

The primary cost component of a zero tolerance policy is the cost of replacing individuals dismissed for failing a urinalysis test. The primary approach for estimating the replacement cost of those dismissed for being drug-positive in 1999 is to assume that 
replacements are acquired via lateral entry much as they are in private firms. That is, a dismissed worker is replaced by simply transferring another worker from a lower grade or from a different occupation at the same grade. This approach may not accurately characterize the military's internal labor market in which there is not lateral entry and all hiring is at the entry point. For example, it does not account for the impact of annual attrition. Nonetheless, it is useful in the cost-benefit analysis (CBA) to generate a lowerbound estimate of replacement costs and a 'best-case’ scenario for the drug program.

To estimate replacement costs per new accession we used the DMDC data on those dismissed by the Navy in 1999, disaggregated by pay grade, tenure, and military occupation. Per person training and recruiting costs were taken from the Navy's Manpower Cost Estimating Model. Training and recruiting costs for individuals in designated military occupations range from $\$ 7,151$ for the Counselor occupation to $\$ 46,067$ for an Electrician’s Mate. For recruits with no occupation, per person cost is $\$ 6,858$; for apprentices with no occupation but who completed advanced training, cost is $\$ 21,950$. For all others we use average Navy-wide replacement costs of $\$ 17,344 .^{13}$ Total replacement costs are the product of the number of required new accessions and the cost per accession. Under the lateral entry replacement assumption the cost of replacing Navy personnel dismissed in 1999 under zero tolerance is $\$ 71.1$ million.

Direct program costs include medical labs, salaries of program employees, and other administrative costs. In 1999 the Navy spent \$17.5 million to administer the drugtesting program. ${ }^{14}$ In addition, each service member is tested 2.4 times a year on average, which generates lost work time. Lost output from the testing process is obtained by multiplying the 2.4 tests per person by the time to take the test (10 minutes) and then by 
the size of the work force. The total time loss is roughly 52,379 hours. Using an average hourly wage (based on 250 annual work days) of $\$ 11.37$, lost output from the testing process is valued at $\$ 1.4$ million. Total program costs thus range from $\$ 90.6$ million to \$196 million, depending on the replacement assumption.

Table 3 summarizes gross benefits (panel A, total costs (panel B), and net benefits (panel C). Under all estimated parameters, the program generates net economic losses. The losses are the smallest (\$14.89 million) when the impact of drug use on productivity and the deterrence effect are high. At the other extreme, when the lowest values of degradation and deterrence are used losses are as high as $\$ 65.39$ million. The partial sensitivity analysis in Table 3 indicates that net losses are robust to variations in the key parameters. Another way to view these results is to calculate the required level of a given parameter for the program to breakeven. Breakeven degradation factors are .11 (assuming high deterrence) and .15 (assuming low deterrence).

\section{CONCLUSIONS}

Computing the welfare gains of a zero tolerance policy in a comprehensive manner requires numerous assumptions. While these calculations have inherent limitations, we find that for reasonable parameter values there are welfare losses from a zero tolerance policy. If a program yields substantial net benefits using worst case assumptions, the program can be recommended even in the face of considerable uncertainty about the exact magnitude of the benefits. In this case, however, the military's drug program generates positive net benefits only when key parameters are implausibly high. Even a productivity degradation factor of .11 exceeds our upper-bound estimate of .092, which itself is likely to overstate the true productivity losses associated 
with drug use in the Navy. The fact that private firms are able to adjust wages to reflect the damages imposed by drug abusers, but that prior studies of private sector wages have not detected a consistent pattern of reduced wages for drug users suggests that damages imposed by drug use in the workplace may be closer to, or below, our lower-bound degradation factor (.037).

The negative net benefits in this study suggest that the considerable resources devoted to drug prevention in the military could be reallocated to other prevention efforts such as counseling, rehabilitation, or education. ${ }^{15}$ Prior to 1981 the Navy referred drug abusers to rehabilitation and the available evidence suggests that treatment programs were cost-effective. ${ }^{16}$ Indeed, rehabilitation normally will be more cost-effective than a zero tolerance policy because a major portion of the benefits of rehabilitation are avoided replacement costs. Decision makers also may maximize net benefits by selecting a combination of policies, which might include a 'two- or three-strikes' option along with rehabilitation.

Even though the drug prevention program yields net economic losses, decision makers may be willing to accept them if other, non-quantifiable benefits are sizeable or highly valued. For example, analysts have pointed out that in organizations such as the military and law enforcement, drug testing enhances the public's trust and support for the organization (Felman and Petrini 1988). Greater public support can enhance the organization's effectiveness and its ability to successfully achieve its goals. Secondly, the military is a highly visible organization that may serve as a role model for youth, which may generate external social benefits from its drug policy. 
There are, on the other hand, non-quantifiable costs of zero tolerance that also must be weighed and that are not internalized by military decision makers. For example, drug screening will likely reduce the number of qualified military applicants who are non-users, as well as those who are users, because potential applicants may wish to avoid the invasion of privacy and mis-trust implied by random drug testing. Also, there may be a loss of reputation and future civilian employability of individuals simply because they failed a urinalysis test.

Furthermore, Cowan (1987) claims that the recovery rate in employer-sponsored treatment programs is between $60 \%$ and $90 \%$ for alcohol and drug abusers if the worker remains employed, but is only $5 \%$ if the individual becomes unemployed. This suggests that a zero tolerance policy that fires a drug-positive worker not only creates an unemployed worker who may receive unemployment insurance and who may be less employable, but also by not referring the worker to treatment may prolong the worker's drug or alcohol problem thus imposing secondary social costs.

This study represents a first effort to estimate the economic value of workplace drug programs. The estimates should be considered provisional as additional research is needed to improve the estimates of the key parameters that are so crucial to total program benefits. It is hoped that our paper narrows the range bracketing the true deterrence effect and productivity degradation factors. We argue that the true size of these parameters lie closer to the low end of the range estimated reported here, but it remains for future researchers to identify these effects more precisely and to confirm whether net social costs can be expected in other workplaces. ${ }^{17}$ 
ACKNOWLDEGEMENTS:. We thank Rosalie Pacula for helpful comments and Markus Hey, Mary Jane McCrae, Antonio Martinez and Melissa Potter for research assistance. 


\section{REFERENCES}

American Management Association (2001) Workplace testing: Medical testing. New York.

American Management Association (1996) AMA Survey: Workplace drug testing and drug abuse policies, Summary of key findings. New York.

Borack, J. (1997) A technique for estimating the probability of detecting a non-gaming drug user, The American Statistician, 51: 134-136.

Borack, J. (1995) A procedure for estimating the probability of detecting a gaming drug user, Navy Personnel Research and Development Center. San Diego.

Bray, Robert M., et al. (1995) 1995 Department of defense survey of health related behaviors among military personnel. Research Triangle Park, NC: Research Triangle Institute.

Bray, R.M., M. Marsden, J. R. Herbold, and M. R. Peterson (1992) Progress toward eliminating drug and alcohol abuse among U.S. military personnel, Armed Forces and Society, 18: 476-496.

Bray, R.M., and Marsden, M.E. (1995) Trends in alcohol, illicit drug, and cigarette use among U.S. military personnel: 1980-1992, Armed Forces and Society, 21(2), Winter: 271-293.

Burt, M., M. Biegel, Y. Carnes, and E. Farley (1980) Worldwide survey of nonmedical drug use and alcohol use among military personnel. Bethesda, MD: Burt Associates.

Cook, R., A. Bernstein, and C. Andrews (1997) Assessing drug use in the workplace, in L. Harrison and A. Hughes (eds.), The Validity of Self-Reported Drug Use, National institute of drug abuse, NIDA Monograph \#167.

Cowan, Terrence R. (1987) Drugs and the workplace: to drug test or not to test, Public Personnel Management, 16(4), Winter: 313-322.

Devine, P., S. Bishop, and J. R. Mensch (1989) Cost benefit study of the navy’s level III alcohol rehabilitation program. Caliber Associates.

DiNardo, John (1994) A critical review of the estimates of the costs of alcohol and drug use, in S. Macdonald and P. Roman (eds.), Research Advances in Alcohol and Drug Problems, Vol. II: Drug Testing in the Workplace. New York: Plenum.

Felman, J. and C. Petrini (1988) Drug testing and public employment: toward a rational application of the fourth amendment, Law and Contemporary Problems, 51(1), 253-297. 
French, M.T., G. A. Zarkin, and L.J. Dunlap (1998) Illicit drug use, absenteeism, and earnings, Contemporary Economic Policy, 16 (3), July: 334-346.

Goldberg, L., D. Elliot, D. MacKinnon, E. Moe, K. Kuehl, L. Nohre, and C. Lockwood (2003) Drug testing athletes to prevent substance abuse: background and pilot study results of the SATURN study, Journal of Adolescent Health, 32 (1), January: 16-25.

Harrison, L. and A. Hughes (1997) The validity of self reported drug use, national institute of drug abuse, NIDA Monograph \#167, Rockville, MD.

Hartwell, T., P. Steele, M. French, and N. Rodman (1996) Prevalence of drug testing in the workplace. Monthly Labor Review, 119(11), 35-42.

Harwood, Henrick, Diane Napolitano, Patricia Kristiansen, and James Collins (1984) Economic cost to society of alcohol, drug abuse, and mental illness, 1980. Research Triangle Institute.

Harwood, H., D. Fountain, and G. Livermore (1998) The economic costs of alcohol and drug abuse in the U.S. 1992. National Institute on Drug Abuse, Rockville, MD.

Horgan, J. (1990) Test negative: a look at the 'evidence' justifying illicit-drug testing, Scientific American, March 18, p. 22.

Ippolito, Richard A. (1996) A study of wages and reliability, Journal of Law and Economics. 9 (April), 149-189.

Lieberwitz, Risa L. (1994) Constitutional and statutory treatment of drug testing in the U.S., in S. Macdonald and P. Roman (eds.), Research Advances in Alcohol and Drug Problems, Vol. II: Drug Testing in the Workplace. New York: Plenum.

Macdonald, Scott and Samantha Wells (1994) The impact and effectiveness of drug testing programs in the workplace, in S. Macdonald and P. Roman (eds.), Research Advances in Alcohol and Drug Problems, Vol. II: Drug Testing in the Workplace. New York: Plenum.

Martin, Jack, Joan Kraft, and Paul Roman (1994) Extent and impact of alcohol and drug use problems in the workplace, in S. Macdonald and P. Roman (eds.), Research Advances in Alcohol and Drug Problems, Vol. II: Drug Testing in the Workplace. New York: Plenum.

Martinez, Antonio (1998) A statistical analysis of the deterrence effects of the military services’ drug testing programs, master's thesis, Naval Postgraduate School, Monterey, CA. 
McGuire, T.G., and Ruhm, C.J. (1993b) Workplace drug abuse policy, Journal of Health Economics, 12(2), 19-38

Normand, Jacques (1994) Under the Influence? Drugs and the American workforce. National Academy Press, Washington, DC.

Substance Abuse and Mental Health Service Administration (1996) National household survey of drug abuse: population estimate 1995, U.S. Department of Health and Human Services. Washington, DC.

Wooldridge, Jeffrey M. (2002) Econometric Analysis of Cross Sectional and Panel Data. MIT Press, Cambridge, MA.

Zwerling, C., J. Ryan, and E. Orav (1992) Costs and benefits of preemployment drug screening, Journal of the American Medical Association, 267 (1): 91-93. 
Table 1

Summary Statistics

\begin{tabular}{lcccc}
\hline & \multicolumn{2}{c}{ Military } & \multicolumn{2}{c}{ Civilian } \\
\cline { 2 - 5 } Past month drug use & Before & After & Before & After \\
\cline { 2 - 5 } Past year drug use & 0.195 & 0.025 & 0.322 & 0.146 \\
& 0.389 & 0.056 & 0.424 & 0.234 \\
Married & 0.486 & 0.647 & 0.369 & 0.357 \\
African-American & 0.179 & 0.176 & 0.103 & 0.214 \\
Hispanic & 0.050 & 0.092 & 0.055 & 0.300 \\
Other race/ethnicity & 0.029 & 0.071 & 0.031 & 0.028 \\
High school diploma & 0.444 & 0.378 & 0.334 & 0.352 \\
Some college & 0.303 & 0.513 & 0.254 & 0.201 \\
College diploma & 0.088 & 0.073 & 0.074 & 0.089 \\
Ages 17-20 & 0.270 & 0.119 & 0.324 & 0.243 \\
Ages 21-25 & 0.327 & 0.259 & 0.290 & 0.222 \\
Ages 26-34 & 0.195 & 0.248 & 0.189 & 0.361 \\
Ages 35-49 & 0.206 & 0.378 & 0.195 & 0.173 \\
Number of observations & 10,358 & 10,143 & 1,702 & 3,933 \\
\hline
\end{tabular}

Note: Males aged 17 to 49. Computed from NHSDA and DHS surveys. 
Table 2

Difference-in-Difference Model

\begin{tabular}{lc}
\hline \multicolumn{1}{c}{ Variable } & Estimate \\
\hline Married & -0.784 \\
& $(0.031)$ \\
Female & -0.447 \\
& $(0.035)$ \\
African-American & -0.160 \\
Hispanic & $(0.035)$ \\
& -0.389 \\
Asian, Native-American & $(0.048)$ \\
Military & -0.293 \\
& $(0.081)$ \\
Year95 & 0.107 \\
& $(0.045)$ \\
Military x Year95 & -0.713 \\
& $(0.048)$ \\
& -1.410 \\
& $(0.065)$ \\
\hline
\end{tabular}

Notes: $N=39,640$; standard errors in parentheses.

Dependent variable is the probability of drug participation in last year. Regressions also include three age dummies and three education dummies.

${ }^{a}$ Implied probability effect. 
Table 3. Summary of Cost and Benefits (\$ millions)

\section{Degradation Factor}

\begin{tabular}{|c|c|c|c|}
\hline Low $^{a}$ & ${\underline{\text { High }^{b}}}$ & $\underline{\operatorname{Low}}^{\mathrm{a}}$ & ${\underline{\text { High }^{b}}}^{\text {b }}$ \\
\hline 30.44 & 75.71 & $\ldots$ & - - \\
\hline 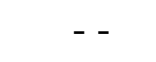 & & 25.21 & 62.68 \\
\hline 90.6 & 90.6 & 90.6 & 90.6 \\
\hline$<60.16>$ & $<14.89>$ & $<65.39>$ & $<27.92>$ \\
\hline
\end{tabular}

Notes: ${ }^{\text {a }}$ Low degradation factor $=-.037$

${ }^{\mathrm{b}}$ High degradation factor $=-.092$

${ }^{\mathrm{c}}$ Low deterrence effect $=+7.88$ pts.

${ }^{\mathrm{d}}$ High Deterrence effect $=+9.82$ pts. 


\begin{tabular}{|c|c|c|c|c|c|c|c|}
\hline \multicolumn{8}{|c|}{ Appendix Table. Net Benefit Sensitivity Analysis } \\
\hline & & \multicolumn{6}{|c|}{ Degradation Factor } \\
\hline & & 0 & 0.037 & 0.092 & 0.12 & 0.15 & 0.18 \\
\hline \multirow{11}{*}{ 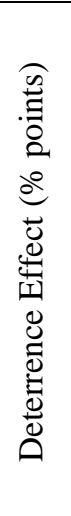 } & 0 & $(196.0)$ & $(191.8)$ & $(185.6)$ & $(182.4)$ & $(179.0)$ & $(175.6)$ \\
\hline & 2 & $(196.0)$ & $(186.5)$ & $(172.4)$ & $(165.3)$ & $(157.6)$ & $(149.9)$ \\
\hline & 4 & $(196.0)$ & $(181.2)$ & $(159.3)$ & $(148.1)$ & $(136.1)$ & $(124.1)$ \\
\hline & 6 & $(196.0)$ & $(176.0)$ & $(146.1)$ & $(130.9)$ & $(114.7)$ & $(98.4)$ \\
\hline & 8 & $(196.0)$ & $(170.7)$ & $(133.0)$ & $(113.8)$ & $(93.2)$ & $(72.7)$ \\
\hline & 10 & $(196.0)$ & $(165.4)$ & $(119.8)$ & (96.6) & (71.8) & (46.9) \\
\hline & 12 & $(196.0)$ & $(160.1)$ & $(106.7)$ & (79.5) & (50.3) & (21.2) \\
\hline & 14 & $(196.0)$ & (154.8) & (93.5) & (62.3) & $(28.9)$ & 4.5 \\
\hline & 16 & (196.0) & (149.5) & (80.4) & (45.2) & $(7.4)$ & 30.3 \\
\hline & 18 & $(196.0)$ & $(144.2)$ & $(67.2)$ & (28.0) & 14.0 & 56.0 \\
\hline & 20 & $(196.0)$ & (138.9) & (54.1) & (10.9) & 35.4 & 81.7 \\
\hline
\end{tabular}

\footnotetext{
${ }^{1}$ A recent survey found that 50 percent of large U.S. firms test current employees, and 60 percent test job applicants (AMA, 2001). Macdonald and Wells (1994) survey eight types of drug testing programs.

2 The Omnibus Transportation Employee Testing Act of 1991 requires employers in the transportation industry to test all workers who hold safety-sensitive jobs.

${ }^{3}$ Both civilian and military workers are equally subject to state laws governing illegal substance possession and use.

${ }^{4}$ Illicit drug use peaked in 1979 and started to decline after 1981 (Harwood et al. 1998).

${ }^{5}$ Martinez (1998) surveys the evolution of the four service's drug policies.

${ }^{6}$ Note that using the all-industry civilian comparison group may not be a serious flaw. While some civilian workers face drug testing of some type, few face the frequent random testing imposed by the military, and virtually none face a zero tolerance policy (see Macdonald and Wells, 1994). To the extent that some members of the comparison group are tested the regression estimates will understate the deterrence effect. This is acceptable given that our goal is to create a conservative estimate of the deterrence effect.

${ }^{7}$ If firms can shift the costs imposed by drug-using employees, hedonic wage studies would provide useful information on productivity losses from worker drug use. Unfortunately, a large literature that has used this approach has found widely varying results, including a positive relationship between drug use and wages (French, et al., 1998 survey this literature). Note that if firms can shift the costs of drug use to workers in the form of lower wages, there is little incentive to use drug tests. Drug testing is efficient only if drug abusers impose external costs, productivity is hard to measure, or wages cannot be adjusted for individual productivity differences. Administrative wage setting is one reason drug testing may be efficient in the military.

${ }^{8}$ Each incident of tardiness, leaving work early, and performing below normal was weighted by .25 days; each absence was weighted by 1.0; and, an injury was weighted by 5.0 days.

${ }^{9}$ DiNardo (1994) points out that if employers pay workers the value of their marginal products, a worker's decision to miss work is fully internalized via a lower wage (so long as absenteeism does not create negative externalities). As noted above administrative wage setting prevents military wages from adjusting to marginal changes in work effort and absenteeism. Moreover, absenteeism is likely to generate externalities in the military's team production environment, which increases military manpower expenditures and reduces unit production.

${ }^{10}$ By way of comparison, Ippolito (1996) found that the wage discount for government workers with excessive absences or tardiness is about 7 percent, which is near the middle of our range of lost output estimates.
} 
${ }^{11}$ For comparison purposes we use other sources to calculate alternative estimates of the value of lost productivity per drug user. In 1992 there were an estimated 11.4 million civilian illicit drug users over age 12. Adjusting for the number of users between ages 12 and 18 and the number of unemployed, there were roughly 10 million employed adult drug users. Harwood, et al. (1998) estimate total annual U.S. productivity losses of $\$ 14.2$ billion in 1992, which yields a per worker loss in 1992 of $\$ 1,420$ (\$1,604 in 1999 dollars). This estimate falls near the top of our range of degradation factors. Harwood, et al. also estimate the annual earnings loss per drug dependent worker to be \$2,352 in 1992 (\$2,657 in 1999 dollars), which exceeds the top of our range.

${ }^{12}$ The number of users detected is smaller than the number deterred because the probability of detection is fairly low. Borack $(1995 ; 1997)$ demonstrates that the expected time until detection ranges from one year to as high as ten years for a 'non-gaming' user and even longer for a 'gaming' user.

${ }^{13}$ Estimates of per worker turnover costs in private firms also vary widely. A recent survey reported 15 different estimates of turnover costs for a typical worker (earning $\$ 16,000$ annually): the range in costs is from $\$ 3,500$ to $\$ 25,000$. In private firms direct costs include some training costs, but most firms deliver only specific training. By contrast, the military delivers extensive general training, which boosts costs. (See “Employee Turnovers Costs, 2003," http://www.sashacorp.com/turncost.html).

${ }_{15}^{14}$ Data provided by Navy Bureau of Personnel, Drug Detection and Deterrence Branch.

${ }^{15}$ About one-third of Fortune 500 companies have set up employee assistance programs (EAP) that refer drug abusing employees to treatment programs (Felman and Petrini 1988).

${ }^{16}$ Devine et al. (1989) obtained a benefit-cost ratio of 12:1 for the Navy's alcohol rehabilitation program despite the fact that only about 50 percent of participants were successfully rehabilitated.

${ }^{17}$ Whether the conclusions here apply to private firms is questionable. Damages imposed by drug use may be less when safety is not an overriding issue. On the other hand, private companies may face greater legal liability for damages imposed by drug-using employees. 